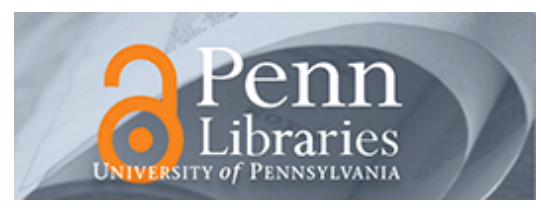

Manuscript Studies

Volume 1

Issue 1 Spring 2017

Article 6

2017

\title{
The Handwritten and the Printed: Issues of Format and Medium in Japanese Premodern Books
}

Linda $\mathrm{H}$. Chance

University of Pennsylvania, Ichance@sas.upenn.edu

Julie Nelson Davis

University of Pennsylvania, jndavis@sas.upenn.edu

Follow this and additional works at: https://repository.upenn.edu/mss_sims

Part of the Asian Art and Architecture Commons, Japanese Studies Commons, and the Medieval

Studies Commons

\section{Recommended Citation}

Chance, Linda H. and Davis, Julie Nelson (2017) "The Handwritten and the Printed: Issues of Format and Medium in Japanese Premodern Books," Manuscript Studies: Vol. 1 : Iss. 1 , Article 6.

Available at: https://repository.upenn.edu/mss_sims/vol1/iss1/6

This paper is posted at ScholarlyCommons. https://repository.upenn.edu/mss_sims/vol1/iss1/6

For more information, please contact repository@pobox.upenn.edu. 


\title{
The Handwritten and the Printed: Issues of Format and Medium in Japanese Premodern Books
}

\author{
Abstract \\ The act of rendering the handwritten in print participates in a long tradition of appreciation of calligraphy \\ in East Asia. This essay considers the question of why manuscript remained the mode for representing \\ writing well after the development of print culture in early modern Japan, forcing us to reexamine our \\ expectations of what the term "manuscript" means: must a work be "written by hand" to be a manuscript, \\ for instance? We argue that the use of print technology as a means to capture and disseminate the \\ calligraphic expands the scope of current notions of what a manuscript is and challenges the model of \\ separation between "manuscript" and "print."
}

\section{Keywords}

Calligraphy, Japan, woodblock prints, manuscript studies, manuscript culture, print culture, material text, palaeography, transcription 


\title{
MANUSCRIPT STUDIES
}

A Journal of the Schoenberg Institute for Manuscript Studies

VOLUME 1, NUMBER 1

(Spring 2016)

\begin{abstract}
Manuscript Studies (ISSN 2381-5329) is published semiannually
by the University of Pennsylvania Press
\end{abstract}

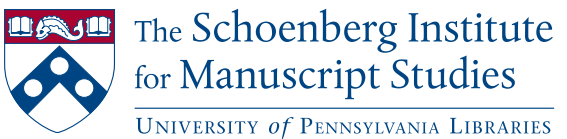




\title{
MANUSCRIPT STUDIES
}

\author{
V OLUME 1, N UMBER 1
}

(Spring 2016)

\section{ISSN 2381-5329}

Copyright (C) 2016 University of Pennsylvania Libraries and University of Pennsylvania Press. All rights reserved.

Published by the University of Pennsylvania Press, 3905 Spruce Street, Philadelphia, PA 19104.

Printed in the U.S.A. on acid-free paper.

Manuscript Studies brings together scholarship from around the world and across disciplines related to the study of premodern manuscript books and documents, with a special emphasis on the role of digital technologies in advancing manuscript research. Articles for submission should be prepared according to the Chicago Manual of Style, $16^{\text {th }}$ edition, and follow the style guidelines found at http://mss.pennpress.org.

None of the contents of this journal may be reproduced without prior written consent of the University of Pennsylvania Press. Authorization to photocopy is granted by the University of Pennsylvania Press for libraries or other users registered with Copyright Clearance Center (CCC) Transaction Reporting Service, provided that all required fees are verified with CCC and paid directly to CCC, 222 Rosewood Drive, Danvers, MA 01923. This consent does not extend to other kinds of copying for general distribution, for advertising or promotional purposes, for creating new collective works, for database retrieval, or for resale.

\section{SUBSCRIPTION INFORMATION:}

Single issues: $\$ 30$

Print and online subscriptions: Individuals: \$40; Institutions: \$90; Full-time Students: $\$ 30$ International subscribers, please add $\$ 18$ per year for shipping.

Online-only subscriptions: Individuals: $\$ 32$; Institutions: $\$ 78$

Please direct all subscription orders, inquiries, requests for single issues, address changes, and other business communications to Penn Press Journals, 3905 Spruce Street, Philadelphia, PA 19104. Phone: 215-573-1295. Fax: 215-746-3636. Email: journals@pobox.upenn.edu. Prepayment is required. Orders may be charged to MasterCard, Visa, and American Express credit cards. Checks and money orders should be made payable to "University of Pennsylvania Press" and sent to the address printed directly above.

One-year subscriptions are valid January 1 through December 31. Subscriptions received after October 31 in any year become effective the following January 1 . Subscribers joining midyear receive immediately copies of all issues of Manuscript Studies already in print for that year.

Postmaster: send address changes to Penn Press Journals, 3905 Spruce Street, Philadelphia, PA 19104.

Visit Manuscript Studies on the web at mss.pennpress.org. 


\title{
The Handwritten and the Printed
}

\section{Issues of Format and Medium in Japanese Premodern Books}

\author{
Linda H. Cha NCE \\ University of Pennsylvania \\ Julie Nelson Davis \\ University of Pennsylvania
}

\begin{abstract}
C
Oonsider figure 1. In a workshop for the 6th Annual Schoenberg Symposium on Manuscript Studies in the Digital Age, held 21-23 whether the text it features was handwritten or printed. Most guessed that it was handwritten, and gasps went around the room when we revealed that it is a page from a woodblock printed book. In truth the workshop participants were on the right track: the makers of this book intended that this preface should look like a manuscript. The preface was designed, rendered, and reproduced with the intention of preserving the illusion of the handwritten while profiting from making multiples. This is manuscript in print.

In this essay we reprise-and ruminate upon-our workshop presentation, to contemplate why looking at a preface such as this brings forward the ways in which manuscript remained the mode for representing writing well after the development of print culture in early modern Japan. For those of us who study early modern Japanese printed books the fact that this book should feature an elegant calligraphy facsimile seems entirely natural, as this was quite common for printed books throughout the period. ${ }^{1}$ This
\end{abstract}

1 By early modern, we mean the seventeenth, eighteenth, and first half of the nineteenth centuries. 
Manuscript Studies, Vol. 1 [2017], Iss. 1, Art. 6

Chance and Davis, The Handwritten and the Printed | 91

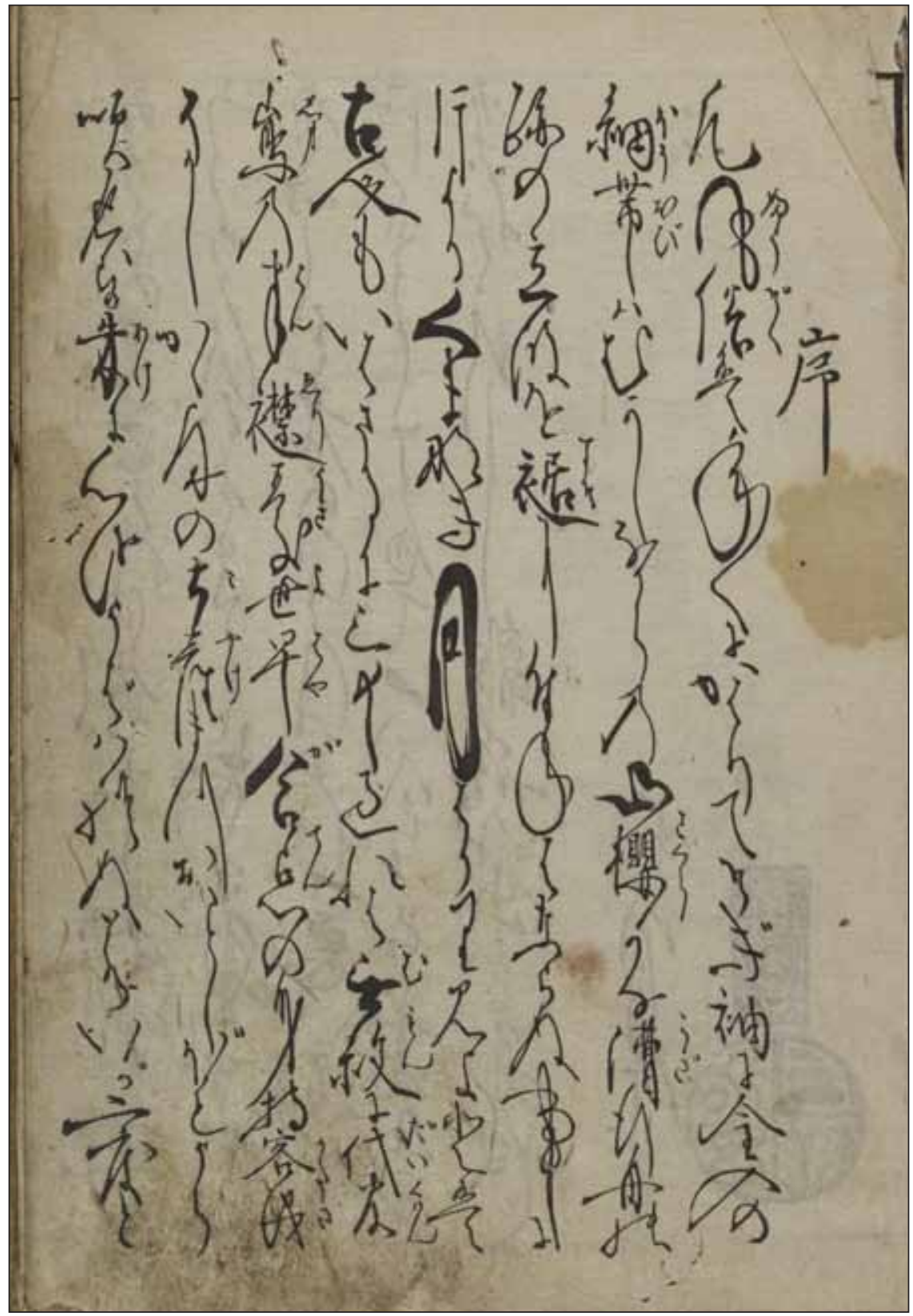

Figu RE 1. Preface, Pattern Book: Moon through the Pine Trees (Hiinagata: Matsu no tsuki), 1697. Preface by Tachiba Fukaku (1662-1753), illustrated by Buheiji, published by Yamaguchiya Gonbē. Woodblock-printed illustrated book. University of Pennsylvania Libraries, Rare Book and Manuscript Library, TT504.6.J3 B84 1697. 
frontispiece was produced through the technology of woodblock printing (xylography or woodcut). That this was achieved well after the technology of movable type was employed and ultimately abandoned in Japan is in part due to the continued cultural significance and the aestheticization of the handwritten. The separation made between the handwritten and the printed that occurred in Europe-and the resulting invention of "manuscript" as an epistemological category ${ }^{2}$ — did not have similar weight in Japan. Instead, as this example demonstrates, printing became a vehicle for manuscript. The intention was to have no gap between the printed and the handwritten. Printing made the handwritten available in multiple.

For the text shown in figure 1, the publisher commissioned the writercalligrapher to provide this elegant preface. The publisher also hired an illustrator to make the pictures of kimono designs that follow, and these, too, call on a host of visual allusions (fig. 2). These choices demonstrate that the publisher, calligrapher, and illustrator could rely upon cultural standards of appreciation for visual and verbal imagery to lend stature to the entire project. The publisher likewise employed carvers to render text and image into the cherry-wood blocks, no doubt selecting masters known for their skill in meticulous copying, producing what stand as facsimiles of the calligrapher's and designer's brushes. (One might argue that the act of retaining these hands in the printed works elides the contribution of the carver and lends authority to the calligrapher and designer, in the manner of the author effect.)

The act of rendering the handwritten in print participates in a long tradition of appreciation of calligraphy in East Asia. In both the practice of calligraphy and in its connoisseurship, the calligrapher's rendition of each element, from the form of the character itself to its treatment, represents a choice from a shared history of sources. Readers would have been expected to appreciate and understand those choices, seeing them as an extension not only of the brush but of the personality of the calligrapher himself. This writer's seals are Tachiba Fukaku (1662-1753), a prominent poet in the haikai tradition. The

2 See Peter Stallybrass's discussion of "manuscript" as a term and its effects in "Printing and the Manuscript Revolution," in Explorations in Communication and History, ed. Barbie Zelizer (New York: Routledge, 2008), 114-15. 


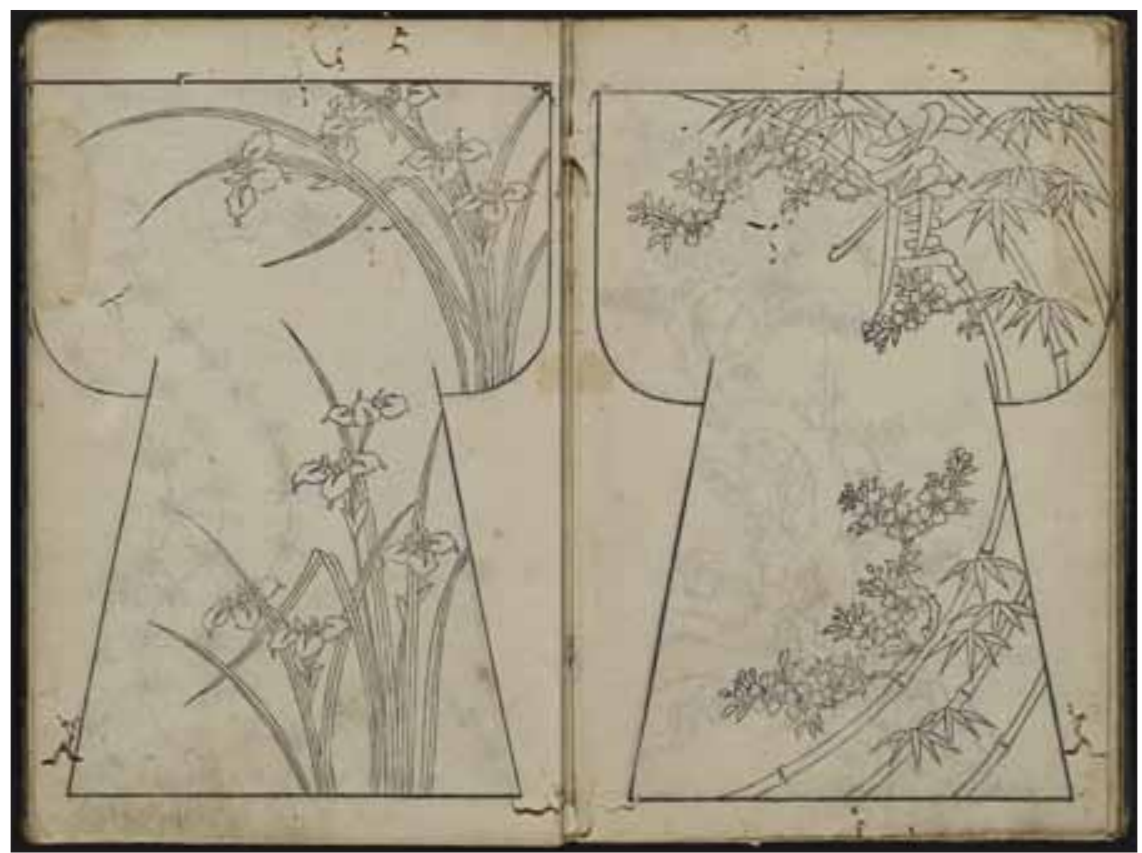

Figure 2. Kimono pattern design, Pattern Book: Moon through the Pine Trees (Hiinagata: Matsu no tsuki), 1697. University of Pennsylvania Libraries, Rare Book and Manuscript Library, TT504.6.J3 B84 1697.

elegance and artifice of this preface is designed to match the kimono styles that follow, with these, too, inflected with cultural meaning. The book as a whole invokes a cultural connoisseurship that is meant to complement (as well as promote) kimono design as a similarly high art. ${ }^{3}$

A final point is worth making about this preface now: it is hard to read. It would be hard for a native speaker who has come through the modern curriculum that relies on printed textbooks and limited character choices. It uses non-standard orthographic forms, premodern grammar, and allusions to classical texts. Even readers in early modern Japan needed a high

3 For more on the history of kimono design and related period texts, see Nagasaki Iwao, "Designs for a Thousand Ages: Printed Pattern Books and Kosode," in When Art Became Fashion: Kosode in Edo-Period Japan, ed. Dale Carolyn Gluckman and Sharon Sadako Takeda (Los Angeles: Los Angeles County Museum of Art, 1992), 95-113. 
level of accomplishment in calligraphy and education in the canonical texts to understand the meaning.

As this example demonstrates, the material text in the Japanese context complicates the concept of "manuscript" and poses several interesting problems for the world history of the book. These texts ask (even demand) that we move "beyond the codex" of our expectations of the "book" as a thing, to rethink the terms of production, presentation, and consumption. We might consider what it means to use the term "manuscript": must a work be "written by hand" to be manuscript? It seems to us that too often the history of the book as a discipline locates a paradigm shift after the arrival of the printing press. In that scenario "manuscript" becomes a category that refers exclusively to the handwritten form, in contradistinction to the printed. ${ }^{4}$ In premodern Japan the handwritten persisted in material texts after the development of print technologies, largely due to preferences for the eccentric, elegant, and stylish. At the time this book was made, early modern Japan was awash in print- sheet prints, books, broadsides, and more-with hundreds of bookseller-publishers making printed things for a large audience with a range of literacy and cultural knowledge. ${ }^{5}$ Although the kinds and qualities of these books varied greatly, due to their social purposes and aesthetic aspirations, what unified them all was that they featured texts with the quirky variations of handwriting. Printing did not unify the graphs into standard forms. Rather, the diversity of the handwritten was being reproduced through the medium of print.

In our view, this use of print technology expands the terrain of "manuscript," and this desire to preserve and perpetuate the handwritten challenges the model of separation between "manuscript" and "print" as a natural evolution. Indeed we may argue that in Japan the handwritten became even more vital and visible after the early modern expansion of print culture. (And this visibility extended into the modern period, without interruption, even after typeset became the norm.)

The emphasis upon the handwritten as a form-in calligraphy, espe-

4 Stallybrass, "Printing and the Manuscript Revolution," 114-15.

5 For an overview, see Katsuhisa Moriya, "Urban Networks and Information Networks," in Tokugawa Japan: The Social and Economic Antecedents of Modern Japan, ed. Chie Nakane and Shinzaburō Ōishi (Tokyo: University of Tokyo Press, 1991), 97-123. 
cially the loosest form, called "grass" or running script—and the preference for individual hands raise further questions about what makes a text legible and how you read an illegible text. Levels of orthographic complexity make us consider how we as scholars learn to unpack difficult script styles and how we train a new generation of scholars to read original manuscripts. Digital tools likewise offer the potential for us to read outside the corpus of transcribed manuscripts. These are large and complex questions, and we hope that by spotlighting some of these issues we can demonstrate how the Japanese case complicates the history of material text. ${ }^{6}$

\section{Reading Writing}

The first challenge to working with original texts from Japan is legibility, even for a case less extreme than the preface that opens this essay. With its multiple orthographies and calligraphic flourishes, premodern written Japanese throws up significant roadblocks to comprehension. Yet the training of young scholars in North America skirts these difficulties by relying on modern printed editions, depriving them and us of necessary exposure to the many ways that real texts represent language. Japanese literary studies is in some ways a victim of its own success. Working assiduously since the late nineteenth century, Japanese scholars have transcribed and set in type the entire canon as well as heaps of noncanonical writing. ${ }^{7}$ But that process has privileged legibility of a certain kind: in the majority of critical editions, scholars make the choice of syllabary uniform, transform traditional and

6 The history of the material text in Japan is too large a topic for this essay. At present the standard text in the field is Peter F. Kornicki, The Book in Japan: A Cultural History from the Beginnings through the Nineteenth Century (Leiden: Brill, 1998), as our frequent citations demonstrate. See also Cynthia Brokaw and Peter Kornicki, eds., The History of the Book in East Asia (Farnham: Ashgate, 2013). There is an extensive literature on this subject in Japanese.

7 These efforts rely on centuries-long traditions of annotation and on early modern collectanea, such as the remarkable Gunsho ruijū (665 volumes containing 1,276 titles) assembled between 1786 and 1819 under the direction of the blind bibliographer Hanawa Hokiichi (1746-1821). 
variant Chinese characters into the modern school set, and add glosses and notes in astonishing quantity. Careful schemes of abbreviations in printed volumes note when a particular form is a collation from various editions. Because there is so much linguistic information in modern printed editions, it may not occur to us that the actual uses of graphs in the source text, not to mention the functions of lineation, spacing, and relations between illustration and text, are in some ways obscured. The tradition has been to reject these factors as insignificant for the meaning, but the moment we encounter a text that is not available in print, we see how important it is to be able to read these "epiphenomena" as well, both for the purposes of transcription and interpretation. Typeset works routinely give detailed information about the source manuscripts, including sizes, bindings, paper types, and so on. Still, to get complete orthographic information on a given manuscript, we have to go back to the original, and we have to be able to read it. Alas, this is no simple feat.

Japan did not have a native orthography. Instead, over time-beginning in about the first century $\mathrm{CE}$ - elites adopted and adapted the Chinese writing system to represent Japanese. ${ }^{8}$ The earliest evidence of Chinese characters on the archipelago appears as inscriptions on coins and swords. Before long Japanese were trying to compose texts themselves (with the help of scribes from the Korean peninsula who had been through a similar

8 David Lurie cites "the classic statement" by George Sansom that regards the use of Chinese characters to write Japanese as a tragedy, but Lurie points out that this view is based on "the bilingual fallacy" and "myths of efficiency" of alphabetic writing, not to mention a teleological notion of writing systems as necessarily progressing toward phonography; Realms of Literacy: Early Japan and the History of Writing (Cambridge, MA: Harvard University Asia Center, 2011), 353-54. Through hundreds of closely argued pages, Lurie establishes that there was no concept of writing Japanese and Chinese languages differently (except in later polemics), and questions the notion that alphabetic writing is superior for all purposes at all times. Although many will argue that the Japanese writing system (and all systems that use Chinese characters) requires more time to learn and is therefore not practical for modern purposes, we have to be careful of projecting our concerns back onto premodern contexts. The cultural benefits that came with the spread of Sinitic characters and a shared canon across Asia, including to Vietnam and Korea, are undeniable, and Lurie argues that Japanese writing systems were flexible and evolved to fulfill needed purposes. 
process of learning to write their native language with borrowed Chinese characters). Certain problems attended efforts to use Chinese graphs in such a way that they could be read as Japanese. No two languages could be much more different structurally. Chinese word order is subject-verbobject, while Japanese is subject-object-verb (with the subject rarely stated, but more often implied by verb endings). A system of glossing called kanbun kundoku operated on the sentence level to bridge (and even at times to creatively highlight) these differences. Kundoku strategies guided the transposition of Sinographs into Japanese word order and the production of supplemental elements of grammar. On the word and syllable levels, Japanese writers used Chinese graphs in a variety of ways, semantically, phonetically, and in playful rebus combinations. The challenges of Japanese agglutination could not be easily met, even so.

Take the Chinese verb, to go (also went, will go, might go, and so on, depending on the context), modern xing. It is one morpheme, and can be represented by the single character 行. Compare an equivalent Japanese verb, to go, yuku, which can appear with a full court press of inflections and modal endings, as for example in norisobiteyukazaritsuran. ${ }^{9}$ Using the single Chinese semantogram 行, you cannot reliably realize the full grammar of the Japanese verb. You needed either to employ many more graphs with a long set of correspondences that would signal the meaning or pronunciation of the inflections, or to rely on the reader to grasp elements of the grammar from context with no written equivalent (what linguists call "zero use"). The solutions that Japanese arrived at were complex, and are still seen in the writing of Japanese today, which employs four distinct orthographies, many Chinese loanwords, and locutions derived from the glossing system. ${ }^{10}$

To be fair, Chinese characters merely comprise a writing system, different from any other orthography only in the fact that the system uses

9 “[Why] did I not go along [riding with her]?” Kitamura Kigin, Genji monogatari kogetsushō, 3 vols. (Kōdansha gakujutsu bunko 14; Tokyo: Kōdansha, 1982), 1:207.

10 Chinese characters (kanji), the square syllabary katakana, which was derived from abbreviation of characters, the rounded syllabary biragana, which was formed through cursivising characters, and the Roman alphabet (römaji). See Lurie, Realms of Literacy, $315-16$ on formations of the syllabary. 
numerous graphs (from about three thousand for the educated contemporary Japanese reader to as many as six thousand for an educated writer of modern Chinese). Much mystification has bewitched the lay public to think of characters as magic ideograms; linguists generally disagree. ${ }^{11}$ We could arbitrarily substitute characters for letters of the alphabet and transcribe all of Shakespeare with one-to-one phonetic correspondences (surely Shakespeare is worthy of this kind of graphic glamour) as in this example:

\section{阿、娜富億喻 凡億億羅哀 気泊億寺娜、 \\ 倭富阿楽哀 迷哀迷億羅夜 富億楽泥寺 安 寺哀安娜哀 \\ 阿怒 娜富阿寺 泥阿寺娜羅安馳娜哀泥 気楽億矛哀： \\ 羅哀迷哀迷矛哀羅＼cjkstart娜富哀哀}

I, thou poore Ghost,

while memory holds a seate

In this distracted Globe:

Remember thee?

-Shakespeare, HamleT $T^{12}$

This is one of the ways Japanese utilized Chinese characters in the eighth century, but they rarely settled for anything so simple. They were having too much fun taking advantage of multiple capacities for visual and verbal play in the creative use of graphs.

Late twentieth-century training has taught many of us to view Chinese texts written in Japan (kanbun) as anomalous (bentai), and to interpret the emergence by the late eighth to early ninth century of two simplified systems for representing the syllables of Japanese as a landmark moment that enabled efficient recording of the vernacular. The common explanation is that the

11 For a lively discussion of ways in which Chinese characters have been misconstrued, see J. Marshall Unger, "Dave Barry and the Intellectuals," in Unger, Ideogram: Chinese Characters and the Myth of Disembodied Meaning (Honolulu: University of Hawai'i Press, 2004), 54-62.

12 And if such a transcription were done without word breaks, in the same way that Chinese and Japanese are written, think how much more beautiful it would be. 
development of these syllabaries made it easier to read Japanese, but this is only partially true at best. Like earlier inventories of graphs used to represent the sounds of Japanese, the syllabaries contained multiple choices of character for each sound. ${ }^{13}$ In standard accounts, we may read that women and children used syllabaries, while men wrote in Chinese, but there were differences in class as well as gender when it came to who read and wrote what. The lines between different styles are nowhere near as clear as we have been told. ${ }^{14}$ Characters were cursivized in varying degrees. A "text for women" in easy syllabary, such as the Onna Imagawa yasakotoba (Imagawa Lessons for Women in Tender Words, 1763), would still incorporate Chinese characters, albeit with pronunciations provided along the side, as well as the kundoku glossing system for the occasional passage in Chinese word order. ${ }^{15}$ This was a primer, it was used to educate girls, and it was normal, or even progressive, in its mix of writing styles. Our contemporary analytical framework that separates the writing of Chinese language from the writing of Japanese vernacular-even as it recognizes the high degree of Sinitic compounds in texts from the medieval era with the term wakan konkōbun (mixed Japanese-Chinese writing) - interferes with reading actual texts. The reader must be prepared to bring a great deal of knowledge and a high degree of flexibility to the task of interpreting premodern texts. It helps to abandon expectations that good writing should be "efficient" in its choice of forms. The problems are potentially multiplied when we look at handwritten exemplars, as well as handwriting in print.

13 The early inventory of Sinographs used to write Japanese phonetically is called man'yogana because it was used most fully in the Man'yōshü anthology. The single syllable $k i$, at the extreme, was written with as many as nineteen different characters. Over time the inventory gradually shrank, and in 1900, alternate choices of kana were dubbed bentaigana (abnormal syllabary) and excluded from basic education.

14 Court women such as Murasaki Shikibu were well versed in Chinese literary classics, while men at court wrote poetry and letters in the vernacular. For more on the way that gender and texts have been polemicized, see Tomiko Yoda, Gender and National Literature: Heian Texts in the Constructions of Japanese Modernity (Durham: Duke University Press, 2004), especially chapter 3.

15 Onna imagawa, by Sawada Kichi, was a popular educational text for women, modeled on the early fifteenth-century Imagawa letter. The yasakotoba version is illustrated by Nishikawa Sukenobu. The text can be viewed at the Kokubungaku Kenkyū Shiryōkan database, base1.nijl.ac.jp, entry number 200013961. 


\section{Embodying Writing}

It is a well-known but still unexplained fact that the Japanese had access to block printing technology early on in the eighth century, and yet mostly rejected it in favor of the laborious business of hand copying. ${ }^{16}$ Hand copies were often produced in the roll format, one of the least convenient (excepting the large stone slab) of book configurations. Why didn't Japanese embrace the efficiency of production and distribution that printing could bring until the seventeenth century, and why didn't the codex-some folded format—claim more space earlier?

Tentative answers to the persistence of hand copying in Japan span the aesthetic dimension and the pragmatic. Before the advent of widespread printing in the late sixteenth century, the written text in Japan was produced by and for social elites, i.e., the court, aristocrats, and literate clergy, who comprised no more than 5 percent of the population. Access was limited. Acquiring, even for a short time, a text of renown or importance (even the paper upon which to inscribe one) was an event worthy of recording in history, as the journals of many nobles attest. ${ }^{17}$ As our kimono pattern preface suggests, the effort to enhance the beauty of a text could certainly come at the expense of easy readability-for anyone outside the narrow circle at which a text was aimed, at least.

The scroll was less a method of sharing data than it was of authorizing and limiting transmission to an elite that could afford to reproduce texts by hand. This was true of sacred texts as well as secular stories, but was perhaps most crucial when it came to knowledge practices in the arts (everything from poetry to mounted archery). The recipient of a secret

16 Shōtoku's sponsorship in 764 of the printing of one million Buddhist spell texts (darani) to place inside small wooden pagodas is well known; some printing was done in Buddhist temples intermittently thereafter.

17 A famous example is the author of the so-called Sarashina diary (Sarashina nikki), who prayed for access to the entire text of the Tale of Genji (Genji monogatari) with such fervor that she feared for own spiritual health. Edward G. Seidensticker, trans., As I Crossed a Bridge of Dreams (London: Penguin, 1975), 31, 46. She also was grieved at the death of a woman whom she only knew through having seen the lady's calligraphy. Seidensticker, As I Crossed a Bridge of Dreams, 45-46. 
tradition in an art, or biden, was perforce a member of a small circle who had agreed to treasure the content, and to contribute whatever time, energy, or expenditure was necessary to honor and preserve the material form that the content took as well. ${ }^{18}$ The roll was the prestige format, and no amount of argument that the folded book allows easier access to either individual bits of information or to the overall grasping of content could disturb that hierarchy. In fact, the benefits that a codex could provide were not sought, and thus there was little impetus to change. The student was neither capable of nor expected to "look up" or collate discrete chunks of facts about an art. He was, if anything, actively discouraged from convenient consultation of a well-organized text (what, after all, was the teacher for?). Total understanding of an art was not presumed to be of easy access, nor again desired to be so. Whether authors of texts on arts kept the scroll style because these virtues were not needed, or whether the scroll format helped influence the reign of these preferences in the way that arts were transmitted is impossible to say, but the roll seems paradigmatic in this area. ${ }^{19}$

This should not distract us from the fact that flat books were also quite prevalent. Although the roll form was the first to reach Japan from China, the bound book tradition did as well. This tradition existed in numerous varieties, from the concertina-like oribon so associated with Buddhist texts to the butterfly binding (kochōsō) and the pouch binding, the latter of which dominated after the 1600 printing watershed. Most volumes were slender and soft, and a text would usually be printed in a series of bound volumes, the so-called satsu. These might be grouped together in stiff cardboard folding wrappers, the chitsu, and with or without such integuments, volumes were stacked on their sides on shelves. Peter Kornicki notes that Westerners did not at first recognize Japan as a bookish society because they did not as-

18 See Maki Isaka Morinaga, Secrecy in Japanese Arts: Secret Transmission as a Mode of Knowledge (New York: Palgrave Macmillan, 2005).

19 Perhaps the most extreme example is the use of a scroll to impress the seeker of hidden teachings on the art of blowing wind in Fukutomi sōshi, "The King of Farts." See the Cleveland Museum website. 
sociate soft covers with books. ${ }^{20}$ Some books did have hard covers although this is not often noticed.

Another aspect that we should bear in mind regarding the materiality of the book in premodern Japan is the fetishization of text as object. Reading practices, for some books at least, were modulated to reflect the power of the content. Kornicki offers this passage from Taiki, the diary of Fujiwara no Yorinaga, a scene on the twelfth month, eighth day of 1143 in which Yorinaga prepares to read the Book of Changes thus: "First I placed the book on my desk; after bowing to it twice I began reading. I washed my hands and rinsed my mouth out, and put on my stiff silk eboshi hat and my formal silk nōshi apparel before reading. This is how it will be in the future too, for this book is particularly worthy of respect." 21 The author was not much of a prophet when it came to our modern habits, needless to say, but that is beside the point. A canonical book such as this one was read only with the proper attitude.

A number of text formats bring the body of departed ancestors into the hands of the reader, or more properly chanter, as these tend to be sütra styles. Kuyōkyō, sūtras for recitation in honor of the dead, might be fashioned of paper that was recycled from the departed's personal correspondence by writing directly in kanji over kana syllabary or on the backs of letters. Letters might be reduced to pulp and fashioned into new sheets of paper upon which prayers would be inscribed (shukushikyō), or very rarely, clippings of the dead person's hair might be included in the pulp mixture (mōbatsusukikomikyō). ${ }^{22}$ Such incorporation of the bodily remains of the dead is not unique to Japan, but it forms one pole of the respect for material text.

This kind of fetishization is also one of our stumbling blocks, because Japanese educators are today and traditionally have been invested in notions of moral value around manuscript and handwriting. One is expected

20 Kornicki, The Book in Japan, 26.

21 Kornicki notes that "this passage raises more questions than it answers," since we do not know the derivation of Yorinaga's fastidiousness about reading this book, nor whether it was unique; The Book in Japan, 255.

22 Fujii Takashi, Nihon koten shoshigaku sōsetsu (Osaka: Izumi Shoin, 1991), 130-31. 
to devote years, as the cliché would have it, to developing one's "character" by practicing characters. The assumption that the good person would never hesitate to invest copious amounts of time in the acquisition and polishing of literacy skills encouraged celebration of writing that is not particularly easy. Producers and consumers of premodern texts recognized that difficulty and idiosyncrasy could signify erudition.

Rather than exclude such practices as mere decoration, we need to calibrate them as part of the meaning of our texts. Art historians have done a good job of caring, say, that a statue contains a small rolled text in its base, but for literary history, we generally have chosen to ignore the question of whether a given text was originally produced with a chitsu type fold-around, decorated with a bone tab and brocade cover or not, calligraphed in grass or a stiff hand when writing our critiques of text content and influence. ${ }^{23}$ But the presence of a silk bag or bamboo tube around a text surely tells us something about the value felt to inhere in it, and such investigation has a place in considerations of the reception of individual texts. We have to account for the materiality of texts in our research, because they continue to matter. Today, when virtual reproduction is possible, Japanese publishers persist in producing stunning facsimile editions in lovely wooden boxes. ${ }^{24}$ The ideology of the facsimile edition is close to the manuscript tradition, because it aims to provide uniquely beautiful and satisfying copies at any cost.

Even today, serious and non-serious books alike go into the world wrapped in paper obi bands that both convey an advertisement for the earth-shattering content and demand that the book be pulled on and off the shelf with greater than normal care (fig. 3). The presence of barely worn and rarely torn obi on used books suggests that readers typically do not treat the paper bands as extraneous ephemera. (Notice that we are not cynical enough to assume that such books have simply not suffered reading at the hands of their erstwhile owners.)

23 For art historians, the small texts sometimes provide religious dedications of the statue that give information on provenance; for literary historians, we generally do not have the physical "original" of most texts, so these differences in approach are in some sense logical.

24 Such luxury volume enterprises have declined recently, but not disappeared. 
Chance and Davis: The Handwritten and the Printed

104 | Journal For Manuscript Studies

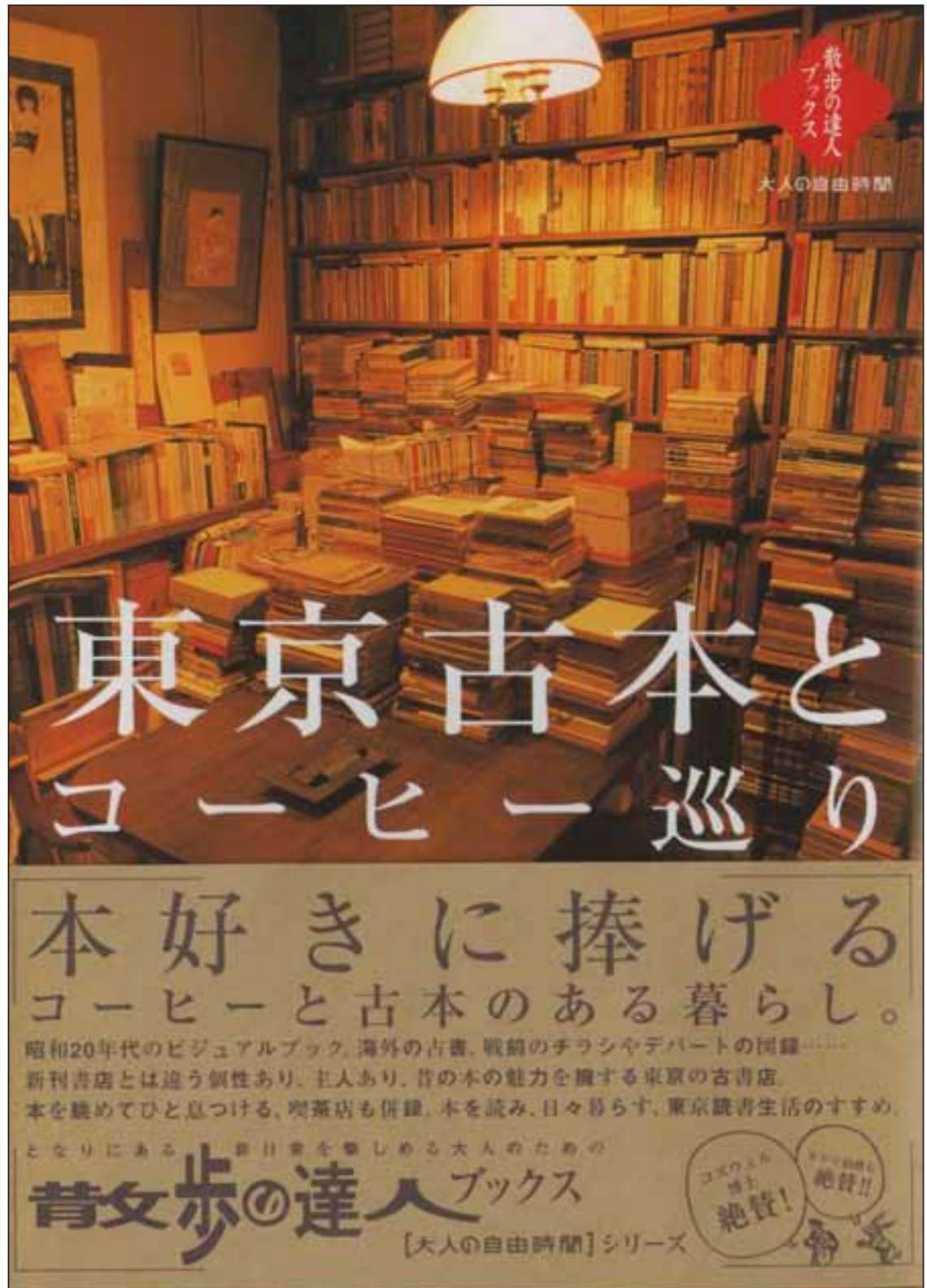

FIgURE 3. This guide to coffeeshops and used bookstores in Tokyo has a brown paper band (obi) that reads "Giving a life of coffee and used books to those who love books." Nakamura Naomi, ed., Tōkyō furuhon to koohii meguri (Kōtsū shinbunsha, 2003). Collection of Linda H. Chance. 
Lest it be thought that the Japanese book is subject to an unrelenting partiality for order and reverence, however, recall this injunction of the mid-fourteenth-century author Kenkō: "Books in a set that are not all the same are considered unsightly, but Kōyū sōzu remarked: 'To always assemble things in sets is what vacuous people do. Incompleteness is best,' and I found this too impressive. Indeed, in all cases, whatever they may be, completed things are unsuitable." ${ }^{25}$ Although in his Tsurezuregusa (Essays in Idleness), from which this observation comes, Kenkō is promoting the peculiarly medieval concern with an aesthetics of impermanence, such sensitivity often surfaces with respect to material culture in East Asia.

Compare the ultimate formless format of the book bag or bag-bookChinese poet Su Dong Po (1037-1101) kept a sack into which he tossed scraps of poetic inspiration, which amounts to self-publishing for the technologically challenged. A bag of poetry scraps is not, you might object, a form of publication, strictly speaking. But we must note that in contrast to the careful production of the decorated scroll, a careless, almost fortuitous, material genesis plays into the authorizing legend of some classic works. The tale of the discovery of Kenkō's corpus, purportedly found pasted to the walls of the author's hermitage after his demise, and described in an apocryphal text Kongyokushü [Collection of Gems] that seems to have surfaced in the 1670s or 1680s, resonated with the contemporary audience. After Kenkō died, his page Myōshōmaru was supposed to have told people

... that there were many discarded scribblings and aimless poems covering the walls of Kenkō's hermitage, and also some which Myōshōmaru himself had preserved as treasured mementos ... About fifty leaves of collected poetry were gathered at the hut in Iga; Tsurezuregusa was brought back as many pieces that had been

25 Linda H. Chance, Formless in Form: Kenkō, Tsurezuregusa, and the Rhetoric of Japanese Fragmentary Prose (Stanford, CA: Stanford University Press, 1997), 207. Tsurezuregusa (Essays in Idleness), section 82. Yasuraoka Kōsaku, Tsurezuregusa zenchūshaku, 2 vols. (Tokyo: Kadokawa Shoten, 1967), 1:351. 
pasted to the walls or written on the backs of copied sütra scrolls at Yoshida. ${ }^{26}$

As these examples show, we will not fully account for the richness of Japanese manuscripts or printing culture until we can make legible all these languages and practices.

\section{Printing Writing}

The preface discussed at the start of this essay is, in effect, made to function as a facsimile of the handwritten; printing made it possible to produce hundreds, if not thousands, of "manuscripts" like this one (see fig. 1). It signals how much the handwritten remained of social and cultural value, for many of the reasons discussed above, but what is worth bringing to bear on this discussion is that those values, as well as pragmatic concerns, seem to have been important in the decision to produce the facsimile through xylography. Another choice was available to its makers: the technology of movable type. However, the limits of movable type as a technology seem to have made it challenging to adapt to the various expectations for text and its presentation in premodern Japan. The fact that a preface such as this one was produced through xylography after a moment when movable type had been introduced-and ultimately abandoned-makes us reconsider how firm the boundaries around print and manuscript were in the period.

As mentioned above, block printing was in use in Japan since the eighth century, and printing was being used to reproduce text for reading in the eleventh century. These earlier projects mainly were in service to Buddhist temples in texts not intended for lay readers or wide circulation. ${ }^{27}$ For many

26 Chance, Formless in Form, 62-63.

27 K. B. Gardner, "Centres of Printing in Medieval Japan: Late Heian to Early Edo Period," in The History of the Book in East Asia, ed. Cynthia Brokaw and Peter Kornicki (Farnham: Ashgate, 2013), 443-55. Also, Peter F. Kornicki, “The Emergence of the Printed Book in Japan: A Comparative Approach," in Recovering the Orient: Artists, 
texts, printing was not the medium of choice to make multiples, as described above; rather the act of copying was still being performed as a manual act. In addition to the scribes employed in the practice of copying, there were many others that copied by hand as part of their devotional, scholarly, or personal practices, typically using the scroll form. ${ }^{28}$

Print was used to reach a wider, more literate and increasingly aspirational (arguably, even bourgeois) audience in the early modern period. This preface to the book of kimono pattern designs is dated to 1697 , and it was a product of this period of expansion; its correlative achievements were increasingly higher levels of skill in carving and printing. The other material elements of its production-from papermaking to hand printing to stitched bindings - and the choices implied in the selection of these as preferred practices-likewise evidence a process of intelligent selection wherein time, cost, and resources are being carefully balanced against profit and viability. In the eighteenth century, as Peter Kornicki writes, "the leap was made from scribal culture to printed culture, and from restricted reading to a national market for the printed book." ${ }^{29}$ Yet this leap was made with handprinted xylography as the technology of choice. How and why movable type was attempted and ultimately abandoned in Japan is another knotty and intricate subject too large for our discussion here, ${ }^{30}$ but let us bring forward

Scholars, Appropriations, ed. C. Andrew Gerstle and Anthony Crothers Milner, Studies in Anthropology and History 11 (Chur: Harwood Academic, 1994), 235-36.

28 Consider, for example, the case of Matsudaira Sadanobu (1759-1829), former councilor to the shogun, and his dedication in copying The Tale of Genji in manuscript, a text that in modern editions numbers up to two thousand pages. The first time it took him one year (1803) to copy out, but this was apparently not enough - he copied it six times more between 1805 and 1822; see Timon Screech, The Shogun's Painted Culture: Fear and Creativity in the Japanese States, 1760-1829 (London: Reaktion, 2000), 40-41. On larger issues of early modern manuscript practices, see Peter F. Kornicki, "Manuscript, Not Print: Scribal Culture in the Edo Period," The Journal of Japanese Studies 32 (2006): 23-52.

29 Kornicki, “The Emergence of the Printed Book in Japan," 237.

30 See Henry D. Smith, "The History of the Book in Edo and Paris," in Edo and Paris: Urban Life and the State in the Early Modern Era, ed. James L. McClain (Ithaca: Cornell University Press, 1994), 332-52; David Chibbett, The History of Japanese Printing and Book Illustration (Tokyo: Kodansha International, 1977), 61-78; Kornicki, The Book in Japan, 128-36, 158-66. 
just a few pertinent factors for why xylography was the preferred means for representing the handwritten in print.

Looking at early modern books, one thing that seems quite clear to us is that retaining variation remained something worth pursuing. Representing handwriting retained its cultural value, as the diversity of hands shown in print suggest. The benefits of xylography to do so seem to have exceeded the potential for all that movable type might achieve. Movable type was used for a number of projects from the later sixteenth century until about 1650, but after that it was rarely employed until the modern era. ${ }^{31}$ As demonstrated in figure 1, there were a number of weighty orthographic choices that needed to be made in writing a word: if it may be written in kanji, should it be written in kanji or in its kana form? If it is in kanji, does it include furigana to the side to facilitate reading? Are the characters joined with ligatures, are they in a line or staggered, and how large or small might they be? These are all seemingly small decisions that express the calligrapher's choices and express his personality, but rendering these in movable type would pose a variety of technical challenges, to say the least.

The attempt to represent calligraphy in movable type had been made early in the century, in one of the landmark early printed books, Ise Monogatari (The Tales of Ise) from 1608. In this text, preference for variation and appreciation of ligature joins meant that the well-known opening to nearly every chapter- "long ago there was a man" (mukashi otoko arikeri)—did not employ the same pieces of type each time that phrase appeared. Rather, mukashi (long ago 昔/むかし) and otoko (man 男/おとこ) might be rendered with either kanji or kana. Type was carved for both variations of kanji and kana, and while it might have been possible to render the verbal, arikeri (ありけり), as four kana (in the manner shown in the parenthesis), this, too, was made in several kana variations, with elegant ligatures. To join the graphic units in this fashion required specially carved blocks of type. What this example shows is that when it might have been possible to create "standard" type, that was not the choice that was made. But perhaps

31 The use of movable type in the modern era was facilitated - as well as necessitatedby the standardization of character forms and other streamlining efforts. 
we should not be surprised, for this book, after all, features the calligraphy of one of the period's most accomplished hands, that of Hon'ami Kōetsu (1558-1637). ${ }^{32}$ To render it without his individual choices would have been to misrepresent his highly appreciated style.

For other projects making enough type to represent the full range of words for a substantial text would likely mean producing thousands, even tens of thousands, of pieces for a single project. Movable type books produced only with Chinese characters, while theoretically simpler than books written with the full complement of Japanese inflections, required enormous resources. Shogun Tokugawa Ieyasu (1543-1616) commissioned a set of 100,000 individual pieces of wooden type for books written in secular Chinese that were printed between 1599 and $1606 .{ }^{33}$ For another project, Ieyasu ordered 89,814 pieces of bronze type be cast for the Chinese characters. ${ }^{34}$ While these and similar products of the early seventeenth century seem to have been about the demonstration of power as much as anything else, what is clear is that for many this kind of investment just for the type would have been prohibitive as well as unwieldy.

A second factor for the continued preference for xylography is the cultural preference for what calligraphers traditionally did: they demonstrated their mastery of the brush, as well as their individuality, in their rendering of the text. For calligraphers, demonstrating an ability to vary forms within a single page is essential, as is displaying through style one's familiarity with notable precedents. In running script, how one spaces the forms across the page is also a sign of artistic skill—scattering and staggering-and joining the forms through ligatures was likewise highly appreciated. When the calligrapher dipped his brush, and which forms were thus darker or thicker, likewise carried meaning, signaling skill as well as the rhythm of the writer's progress through the text.

Let us return to the preface featured in figure 1 to note how it has been designed to reproduce these shifts, swells, curves, and twists of the brush.

32 This may be seen in pages from the book digitized for the Museum of Fine Arts, Boston (accession number 2011.1077.1-2); site accessed June 29, 2014.

33 Kornicki, The Book in Japan, 130.

34 Chibbett, The History of Japanese Printing, 71. 
The page is composed to draw our attention to the character at the center of the page. Its dark tone and larger size (nearly equivalent to two to three characters in the columns on either side) evidence the calligrapher's deliberate emphasis upon this single form: the Chinese character for moon 月. Its visual weight is appropriate for the conceit of the book's title: Pattern Book: Moon through the Pine Trees (Hiinagata: Matsu no tsuki) (and its pun, pining for the moon). It is also where the writer alludes to a well-known phrase from classical literature, which may be rendered thus: "Someone from the past did not say look only at the moon when it is cloudless." ${ }^{35}$ Thinking pragmatically about how to render a single character in print, we imagine that for a publisher with profit on his mind carving a single piece of type for one time use would likely have been considered extravagant (and using it again in the same book would have seemed repetitive to calligraphy aficionados).

Looking now with an eye to the rest of the page, we note that the size variation, visual weight, ligature use, and reading marks that are so deliberately and wittily employed here would be difficult to achieve through the mechanism of movable type. Producing this single page would require a great degree of variation in type, too; readers familiar with premodern calligraphy might note, for example, the three variations shown here for the kana character noの (as well as two derived from 乃 and 能). As noted above, in order to accommodate ligatures between morphemes in movable type, makers would have to produce larger blocks of type with those joins presented, making odd-sized and specialty pieces of type that would be difficult to reuse in other places. Then there is the concern for ink tone, another challenge for carving type, for how might that be done to show the freshly dipped or drying out brush tip? At a moment when block carvers, by now organized into guilds, had developed their skills such that they could reproduce in xylography a wide range of calligraphic hands as well as image designs, woodblock served these needs more fully. Woodcut was the pragmatic choice, the best means of hitting the sweet spot between the

35 Translation, Penn-Cambridge Kuzushiji Reading Group; the source is Tsurezuregusa, cited in Kōsaku, Tsurezuregusa zenchūshaku, 2:13. 
aesthetic representation of text and the efficient use of resources to put the handwritten into print. And in this case, the high quality of the carving attests to the exquisite precision of the unnamed carver who rendered the calligraphy backwards in the surface of the woodblock.

In early modern Japan, xylography offered other benefits for publisherbooksellers seeking to meet these cultural standards. Books and sheet prints were produced in set sizes, from standard-sized blocks and paper; writers composed text and illustrators designed pictures to fit those pages, laying out those pages in their submitted drafts. (There is no need to cast off the text as might be the case for movable type.) Diacritics and glosses were integrated into the text and in the carved block, as may be seen in figure 1 . Varying characters and joining with ligatures were accommodated by the carver, and replicated the choices made by the writer. Illustrators likewise sketched to match page formats and lengths, and when pictures illustrated texts, they were carved into the same block. ${ }^{36}$ Updates were easily made through the insertion of a plug (rather than resetting the page).

Publisher-booksellers stored these blocks for later use. Books were produced in speculative edition sizes, as around the rest of the world, in numbers meant to recoup the initial investment as well as to bear profit. Blocks could be put back into print if demand was greater than initially estimated, or shaved down for reuse if the title was a failure. Books could be assembled in the shops, folded, bound, and sewn; some reports suggest that lessskilled labor, such as that of family members, might have been brought to these tasks. ${ }^{37}$ Blocks could also be sold to another publisher for reprinting. Owning the block was akin to owning the intellectual content. ${ }^{38}$

And yet, although the number of printed books increased dramatically over the early modern period, printing did not replace manuscript. Handwriting predictably was used for such materials as letters, inventories, and reports, along with literary and scholarly texts, among others, for these all

36 Kornicki, The Book in Japan, 138.

37 Lawrence E. Marceau, "Behind the Scenes: Narrative and Self-Referentiality in Edo Illustrated Popular Fiction,” Japan Forum 21 (2010): 403-23.

38 Julie Nelson Davis, Partners in Print: Artistic Collaboration and the Ukiyo-e Market

(Honolulu: University of Hawai'i Press, 2015). 
served other needs (and did not need to be produced in multiple). Due to shogunal edicts prohibiting some topics from print, manuscript served as a means of spreading information, too, often through the lending libraries. ${ }^{39}$ Because the handwritten featured so much in print as well as in manuscript, calligraphy retained its stature as an art form. With calligraphy manuals offering aspirants how-to courses, style books replicating famous hands, etiquette texts explaining letter writing, and others made available through xylography, it might be suggested that the appreciation of the handwritten as an artistic form was further enhanced by printing.

The impression one gains of early modern textual culture is that of astounding variety and form (on a scale where even the kinds of general observations we have made here seem to barely scratch the surface). But what remains throughout is the appreciation for the handwritten. This, we would suggest, means that in Japan manuscript as a conceptual field of production did not decline in response to-nor was it separated from-the category of the printed. Indeed, if we regard the early modern book in Japan as both handwritten and printed, we can state with conviction that manuscript as a form flourished thanks to the technology of printing.

Although book production changed in the modern era with the adoption of movable type, offset printing, and now the digital, the appreciation of the handwritten has remained. Throughout, woodblock printing continued to be deployed to represent manuscript in a wide range of uses. The legacy of the handwritten is present in the contemporary world, visible in materials like manga, children's books, product labels, signs, advertisements, and even instruction books on how to write and read the handwritten-the printed handwritten remains a part of everyday life (fig. 4).

\section{Learning to Read Writing}

The preface with which we began this essay thus brings forward these issues of manuscript, and it asks us to take into account issues of orthography

39 See Kornicki, "Manuscript, Not Print." 
Manuscript Studies, Vol. 1 [2017], Iss. 1, Art. 6

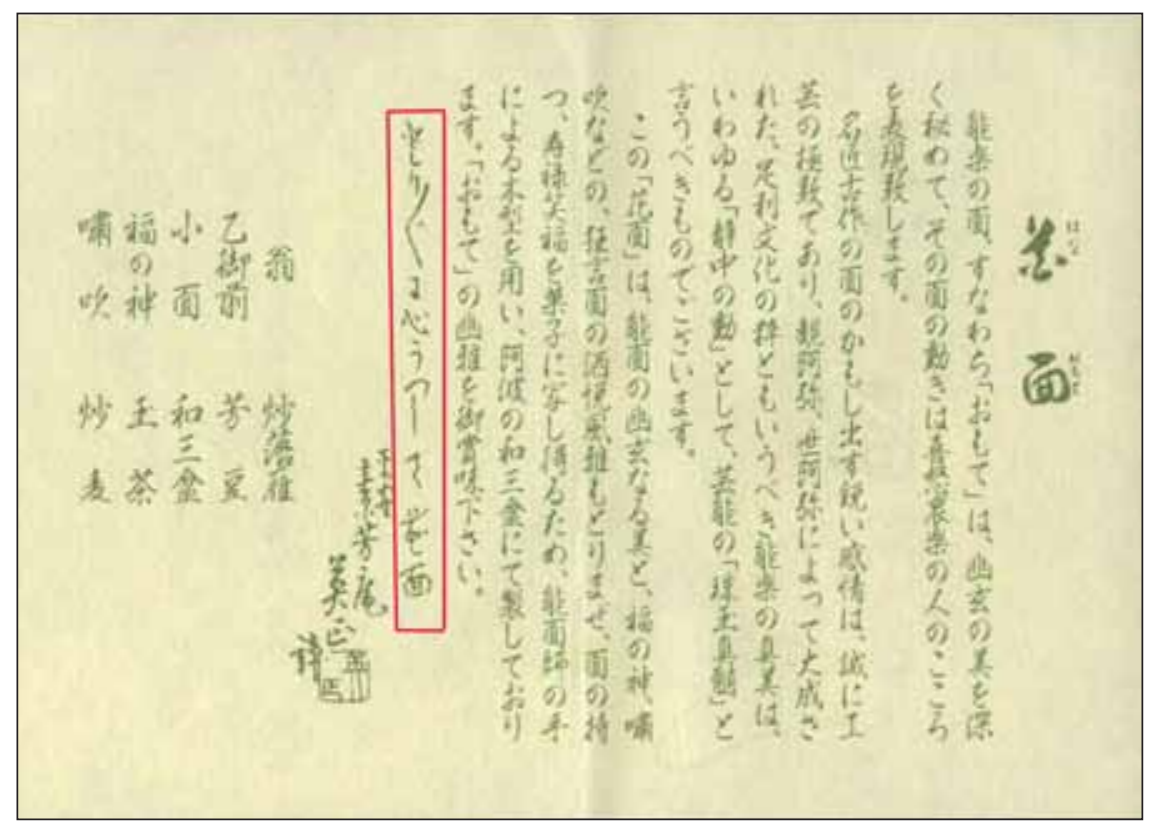

FIGURE 4. Chōkyūdō, a Kyoto maker of Japanese sweets founded in 1831, uses nonstandard kana and kanji in its brochures. Here a haiku reads: toridori ni kokoro utsushite hana omote (Richly expressing the heart, elegant Noh masks). Collection of Linda H. Chance.

and materiality. It was through our mutual interest in the history of the material text in Japan that we began working together to master premodern orthography. ${ }^{40}$ Realizing our project was important to the larger community of scholars at Penn, we also brought together colleagues to form the Faculty Working Group on Reading Asian Manuscripts (RAMS). This group evolved out of a commitment to increasing the contributions of Asianists, and of Penn's Asian manuscript collections, to the study of material texts, one of Penn's great strengths.

In our part of that research group, the Japan-RAMS division, the main

40 For more on these projects, see Jacquie Posey, "Japan-RAMS Scholars at Penn 'Cracking Code' of Early Modern Japanese Manuscripts,” Penn News, 13 September 2013, http://www.upenn.edu/pennnews/news/japan-rams-scholars-penn-cracking-codeearly-modern-japanese-manuscripts, accessed 8 June 2014. 


\section{4 | Journal For Manuscript Studies}

focus is transcribing premodern Japanese texts, both handwritten and printed. Using texts like the preface considered here, at the same time that we are learning to decode premodern manuscript, we are also training the next generation. We recognize that, for the reasons discussed above, reading premodern manuscript hands has not been part of the regular curriculum of language training outside Japan at most universities, and it thus has limited scholarship to the study of transcribed texts. To our knowledge, Penn is at present the only university in North America to have a research group meeting regularly to read premodern orthography. For the past three summers, thanks to the support of the Dean's office, we have offered a three- to four-day workshop, taught by a specialist colleague, Dr. Laura Moretti, from the University of Cambridge, and have drawn participants from across the US and abroad. We continue the program throughout the academic year, working with Dr. Moretti on a weekly basis via Skype, in our Penn-Cambridge Kuzushiji Reading Group. We are also participants in Dr. Moretti's international reading group working to transcribe and translate books held in the University of Cambridge and Fitzwilliam Museum Collections.

The J-RAMS reading group has had quantifiable effects upon our research. Faculty and graduate students alike bring in texts pertinent to their ongoing projects, with works ranging from sheet prints to illustrated books, letters to songbooks, among others. A text such as our preface, admittedly one of the most difficult we transcribed, required that all members of the group put their heads together, search their dictionaries, and make educated guesses. We have read, transcribed, and translated this text and are refining our results for publication on our project website. ${ }^{41}$ Learning so much from this little book would not have been possible without it having recently been added to the Kislak Center collection, and we appreciate the support and challenge that it represents. By bringing the history of the material text in Japan to a larger context, we hope to open up the field to new materials, as well as to boldly read what has not been read before.

41 Penn-Cambridge Kuzushiji Reading Group: https://wordpress.com/read/blog/ id/65794618/ (accessed 8 June 2014). 